\title{
Review Article \\ Essential Hypertension: An Approach to Its Etiology and Neurogenic Pathophysiology
}

\author{
Juan J. Bolívar \\ Departamento de Fisiología, Facultad de Medicina, Universidad Nacional Autónoma de México, Ciudad Universitaria, \\ 04510 México, DF, Mexico \\ Correspondence should be addressed to Juan J. Bolívar; jjboliv@unam.mx
}

Received 22 September 2013; Accepted 6 November 2013

Academic Editor: Francesco Cappuccio

Copyright (C) 2013 Juan J. Bolívar. This is an open access article distributed under the Creative Commons Attribution License, which permits unrestricted use, distribution, and reproduction in any medium, provided the original work is properly cited.

Essential hypertension, a rise in blood pressure of undetermined cause, includes $90 \%$ of all hypertensive cases and is a highly important public health challenge that remains, however, a major modifiable cause of morbidity and mortality. This review emphasizes that, from an evolutionary point of view, we are adapted to ingest and excrete $<1 \mathrm{~g}$ of sodium ( $2.5 \mathrm{~g}$ of salt) per day and that essential hypertension develops when the kidneys become unable to excrete the amount of sodium ingested, unless blood pressure is increased. The renal-mean arterial pressure set-point model is briefly described to explain that a shift of the pressure natriuresis relationship toward abnormally high pressure levels is a pathophysiological characteristic of essential hypertension. Evidence indicating that this anomaly in the pressure natriuresis relationship arises from a sympathetic nervous system dysfunction is briefly formulated, and the most widely accepted pathophysiologic proposal to explain the development of this sympathetic dysfunction is described, with commentaries about novel action mechanisms of some drugs currently used in essential hypertension treatment.

\section{Introduction}

Hypertension, defined as a systolic blood pressure $\geq 140 \mathrm{mmHg}$ and/or a diastolic pressure $\geq 90 \mathrm{mmHg}$, is one of the most common chronic diseases. The overall hypertension prevalence among the adult population was estimated at $26.4 \%$ in 2000 [1]; moreover it has been reported that this prevalence increased from $23.9 \%$, in 1994 , to $29.0 \%$, in 2008 , in the USA [2]; from $25.0 \%$, in 1993 , to $43.2 \%$, in 2006 , in Mexico [3]; and from $15.3 \%$, in 1995, to $24.5 \%$, in 2005, in Canada [4] among other countries. From this prevalence, it is evident that hypertension is a very important public health challenge because its complications, including cardiovascular, cerebrovascular, and renal diseases, are mayor causes of morbidity and mortality. Reducing blood pressure in individuals with hypertension prevents or attenuates these complications $[5,6]$.

Hypertension is due to specific causes in a small fraction of cases, but in the vast majority of individuals $(\approx 90 \%)$, its etiology cannot be determined; therefore, the essential hypertension term is employed $[5,7]$. Essential hypertension is currently understood as a multifactorial disease arising from the combined action of many genetic, environmental, and behavioral factors. Given the multifactorial nature of blood pressure homeostasis, any change in blood pressure as, for example, one due to a mutation, is likely to be compensated by feedback, complementary action, or change, in some other control mechanisms, in an effort to return blood pressure to normal. It is only when the balance between the factor(s) that tend to increase the blood pressure and those that try to normalize it is sufficiently disturbed, when the compensatory mechanisms fail to counteract the perturbation, that essential hypertension results [8]. A century of epidemiological, clinical, and physiological research in humans and animals has provided remarkable insights on the relationships existing between dietary salt (sodium chloride), renal sodium handling, and blood pressure. The evidence points to a causal link between a chronically high salt intake and the development of hypertension, when the kidneys are unable to excrete the ingested amount of sodium unless blood pressure is increased [9-11]. In conjunction with this primary causal factor, a number of adjunctive factors, such as 
obesity, diabetes, aging, emotional stress, sedentary life style, and low potassium intake, may increase the probability of developing hypertension $[10,12]$. Hence, on a similar dietary salt, some individuals develop hypertension while others do not; and the probability to develop hypertension depends on the individual's weight of the hypertension's adjunctive factors.

\section{Control of Blood Pressure by the Kidneys}

The relative stability of arterial blood pressure leads to the conclusion that it is a highly controlled variable. Arterial pressure is maintained at the level satisfactory to ensure an adequate tissue perfusion. Baroreflexes and vasoactive hormones produce tight regulation over relatively short time spans [13]. Long-term regulation is, most generally, thought to be achieved through the renal fluid volume regulation mechanism. Regulation of mean arterial pressure (MAP) requires integrated actions of the physiological systems affecting its major determinants (Figure 1(a)). In the simplest formulation, determinants of MAP are approximated by Ohm's law modified for fluid dynamics (pressure $=$ flow $\times$ resistance). Blood flow depends on cardiac output and blood volume, whereas resistance is primarily determined (as total peripheral resistance) by the contractile state of small arteries and arterioles throughout the body, which is itself determined by the tissues blood flow autoregulation mechanism. Blood volume depends on extracellular fluid volume (ECFV), which itself is determined by the total body sodium content. The latter depends on the balance (sodium equilibrium) between sodium intake and urinary sodium excretion (natriuresis; the main route of body sodium loss). Natriuresis is itself determined by the kidney's perfusion pressure, therefore the application of the pressure-natriuresis concept [8, 13-15]. For the purpose of the following discussion the term "normal sodium intake" refers to the current usual sodium intake (see Section 3 , to realize to what extent this sodium intake is normal).

Long-term regulation of MAP is intimately associated with ECFV homeostasis. Sodium equilibrium is critical to $\mathrm{ECFV}$, and the kidneys, as the principal route through which sodium is eliminated from the body, are therefore central to the long-term stability of MAP. This concept was expressed quantitatively in a systems analysis approach that predicts that the kidney acts as an overriding regulator of arterial pressure through a "renal-body fluid feedback" mechanism. A key component of this feedback is the pressure natriuresis or the effect of arterial pressure on renal sodium and water excretion, exemplified in acute and chronic renal function curves (Figure 1(b); thin and thick curves, resp.). Arterial pressure is set at the level required by the kidney to allow sodium and water excretion to match the intake (point A, Figure 1(b)). Basal-acute and normal-chronic renal function curves (curves 1 and I, resp.) coincide at this pressure level. Kidney perfusion studies show that, in the absence of a change in sodium intake, a rise in MAP (or renal perfusion pressure) is matched by increased renal sodium excretion (point B; sodium excretion exceeds intake), or pressure natriuresis, which reduces ECFV and cardiac output and returns MAP to normal. Therefore, disturbances that tend to increase arterial pressure, such as increased peripheral vascular resistance, would cause only a transient increase in arterial pressure, because they would also provoke increased renal sodium excretion. Conversely, if MAP falls below the control level, a reduced renal sodium excretion (antinatriuresis) increases ECFV and MAP. Hence, the kidney strives to protect against perturbation from the sodium equilibrium set point, and sodium balance and MAP are maintained by a feedback system displaying infinite gain. That infinite gain is invoked to explain the fact that when sodium intake is increased, renal sodium excretion is similarly increased (point C), in response to a very small increase (if any) in MAP, to attain sodium equilibrium. Again, acute and chronic renal function curves (curves 2 and I, resp.) coincide at the new pressure level, because acute renal function curve 2 corresponds to the kidney function influenced by all the regulatory mechanisms triggered by the increased sodium intake (regulatory mechanisms acting to decrease renal tubular sodium reabsorption); and also because the normal-chronic renal function curve I corresponds to the pressure natriuresis relationship observed after all regulatory mechanisms acting at any sodium intake level have influenced the kidney function. When sodium intake is decreased, renal sodium excretion is similarly decreased (point D), in response to a very small decrease in MAP. As expected, acute renal function curve 3 (regulatory mechanisms acting to increase renal tubular sodium reabsorption) and normal-chronic renal function curve I coincide at the slightly decreased MAP level. If this feedback mechanism is valid, hypertension results from a shift in the renal-pressure natriuresis function to the right (chronic renal function curve II), so that a higher pressure is required to attain sodium balance on a normal sodium intake (point E). In this condition, the acute renal function curve 3 and the abnormal-chronic renal function curve II coincide at a hypertensive MAP level. Hence, the acute renal function curve 3 (which corresponds to a situation with regulatory mechanisms acting to increase renal tubular sodium reabsorption) is operative, even when sodium intake is normal. In the presence of hypertension, if sodium intake is increased, a higher than normal MAP increase is necessary to obtain sodium balance (point F) $[8,13-15]$. With the intrinsic kidney function being normal, in the early stage of essential hypertension, an abnormal pressure natriuresis relationship can only result from an abnormal regulation of the kidney function.

\section{Salt Intake}

If the start of human evolution is arbitrarily set at the beginning of the Paleolithic, during 3 million years, the ancestors of humans, like all other mammals, ate a diet containing little sodium and much potassium: some $0.6 \mathrm{~g}$ and $7 \mathrm{~g}$ per day, respectively, a $\mathrm{Na}^{+} / \mathrm{K}^{+}$relationship close to 0.09 [22]. In the Stone Age, the average life span was approximately 30 years. During these times, traits that worked to increase blood pressure with increasing stress would be favorable for survival: people who could easily 


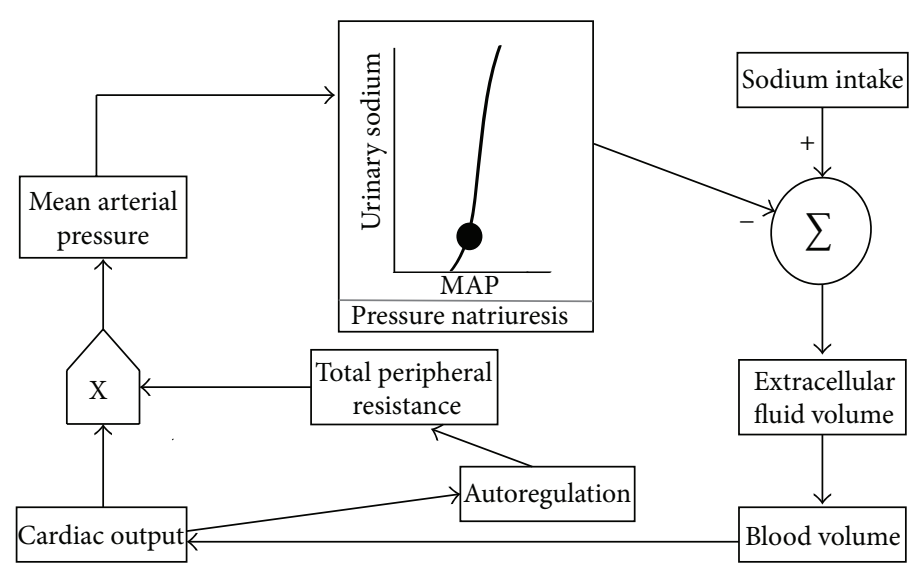

(a)

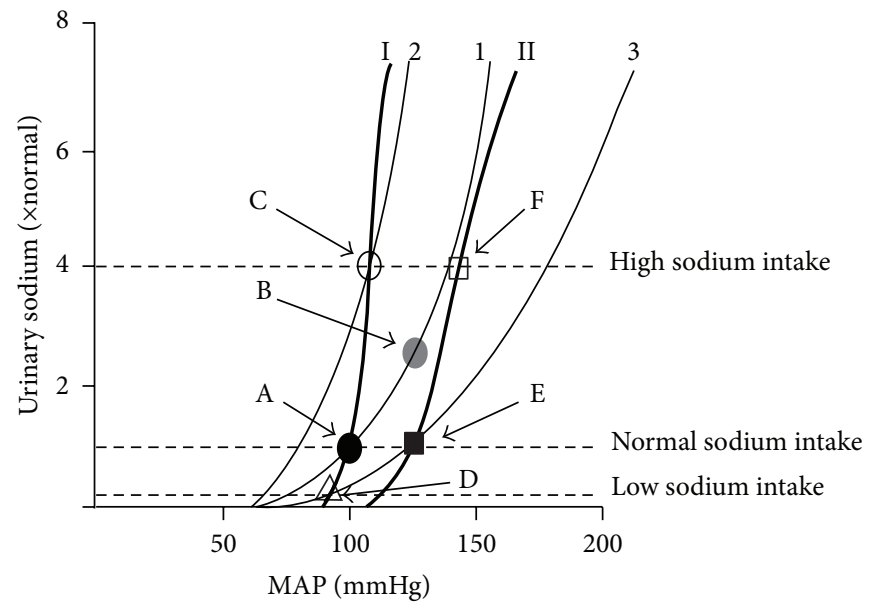

(b)

Figure 1: The renal-mean arterial pressure (MAP) set-point model as proposed by Guyton et al. [13-15]. (a) Basic renal-body fluid feedback mechanism for long-term regulation of blood pressure and body fluid volumes. (b) Normalized urinary sodium excretion is plotted as a function of the MAP to show the pressure natriuresis relationships, at different sodium intake levels, corresponding to the normal condition (acute renal function curves 1,2, and 3 and chronic renal function curve (I)) and to a mild hypertension condition (chronic renal function curve (II) ) . See further details in text.

elevate their blood pressure to provide sufficient blood to skeletal muscles and major organs would have a survival advantage when attacked by enemies or wild animals. Thus, the ability to easily increase blood pressure is a characteristic that might have conferred an evolutionary advantage until modern times [10]. Blood pressure is directly proportional to total body sodium content. As sodium intake is limited in natural foods, physiological mechanisms to promote sodium ingestion and to prevent sodium loss into urine would have been established early in human evolution [23]. To promote sodium ingestion, sodium appetite is a motivated behavioral state, arising in response to sodium deficiency that drives humans to seek and ingest food and fluids containing sodium [24]. To prevent sodium loss, the most powerful mechanism is the renin-angiotensin-aldosterone system (RAAS), which controls kidney's tubular sodium reabsorption and which is maximally activated in people with a minimal sodium intake [10]. In addition, sodium depletion or emotional stress activates the sympathetic nervous system, which, acts mainly via stimulation of the RAAS and further prevents urinary sodium loss $[25,26]$. Besides sodium appetite, evolution has provided humans with a pleasant liking of salt taste, which motivates man to ingest sodium in excesse of need, when it is available [24].

About 8000 years ago, humans discovered that salt could be used to preserve food and developed sophisticated techniques for salt production [27, 28]. Humans then satisfied their innate taste for salt and have been adding it to food ever since $[27,29]$. Salt then became of great economic importance as it made it possible to preserve food, allowing the development of cities. Salt was the most taxed and traded commodity in the world [30, 31]. Romans in the first century AD used salt as money "salarium" and considered it synonymous of health "salus", "salubritas" and more necessary than gold [27, 29]. Hence, due to its use in food preservation, salt consumption was high in historical times, some $10-50 \mathrm{~g} /$ day per person, in Europe in the 18th century, mainly from cured meat and salted fish and meat (implying that salt might be partially 
discarded with the cooking water) [27]. However, with the invention of the deep freezer and the refrigerator (at the end of the 19th century), salt was no longer required as a preservative. Salt intake had been declining, but with the recent large increase in consumption of highly salted (and potassium poor) processed food, salt intake is now increasing towards levels similar to those of the 18th century and is approximately $9-12 \mathrm{~g} /$ day (3.6- $4.8 \mathrm{~g}$ of sodium, that is, 6 to 8 times more than our evolutionary sodium intake), with a sodium/potassium intake ratio $>2$ (more than 20 times our evolutionary ratio), in most countries in the world [22, 31, 32].

Although preference for salty-tasting food and prevention of sodium loss may once have conferred an evolutionary advantage, ingestion of excessive amounts of sodium now results in chronic hypertension $[10,11,24]$. Many large observational epidemiological investigations conducted worldwide link high salt intake and hypertension [30, 33]. In one of the first global studies on sodium intake $[32,34], 24 \mathrm{~h}$ urine sodium and urinary sodium/potassium relationship were positively associated with blood pressure as well as the increase in blood pressure with age. Furthermore, populations with low average daily sodium intake (some tribal societies which do not add salt to the food) had relatively low blood pressure and very little or no increase in blood pressure with age [16]. Hypertension was fairly uncommon in these societies, but individual's blood pressure rose after migration to an urban environment. However, migration involves more change than just a change in salt intake, because other factors, such as mental stress and changes in physical activity and diet, may contribute to the rise in blood pressure [33]. Figure 2(a) shows that in acculturated populations (as the Mexican population), which add salt to the food, systolic and diastolic blood pressure increase with age and that this increase does not occur in nonacculturated populations. In the same way, in acculturated populations (as those of Canada, Mexico, and USA), hypertension prevalence increases with age (Figure 2(b)) $[3,17,18]$. However, blood pressure increase with age is higher in urban than in rural environments, reflecting the environmental influence on blood pressure [35]. On the other hand, in two clinical studies performed on some 200 individuals in which, within their usual diet, dietary sodium intake was randomly and sequentially adjusted at low $(1.15 \mathrm{~g} /$ day $)$, intermediate $(2.30 \mathrm{~g} /$ day $)$, and high ( $3.45 \mathrm{~g} /$ day) levels, during three 30 -day periods, a positive relationship was found between blood pressure and sodium ingestion, supporting the conclusions of the population studies described above $[36,37]$.

In contrast to sodium, potassium was abundant in the fresh food that made up the stone age diet; but, in modern times, diets have shifted drastically to processed foods, reducing potassium intake $[22,31]$. A low potassium diet induces sodium retention and increases blood pressure [38]. On the contrary, potassium supplementation promotes natriuresis and decreases blood pressure [39].

Epidemiological studies worldwide suggest that the optimal daily intake of salt is $5-6 \mathrm{~g}$ [40] and some $3.5 \mathrm{~g}$ of potassium [41], roughly half and twice of the current average intake of sodium and potassium, respectively. However, because humans have evolved with sodium deficiency for a long time, we have developed a powerful hedonistic taste for salt. This innate desire for salty foods, to which cultural and social habits have superimposed, makes it very hard to drastically reduce sodium intake $[10,42]$. Nonetheless, we must realize that the human body is not equipped to handle the unnatural amount of sodium present in our current diet; hence, hypertension, to some extent, may be classified as a disease of "affluence" [11, 42].

\section{Abnormal Regulation of the Kidney Function}

At the end of the 19th century, the renal sympathetic nerves were known to contain fibers which upon stimulation decreased renal blood flow and urinary flow rate. It was also known that renal blood flow and urinary flow rate increased after renal sympathetic nerves transection [43]. In the early decades of the 20th century, faced with the high mortality of severe hypertension and the absence of effective pharmacological therapy, a number of operations on the sympathetic nervous system, such as radical splanchnicectomy, were devised in an attempt to lower blood pressure. By the late 1960s, most of the available antihypertensives, which by then had been developed, antagonized the sympathetic nervous system. The potency and clinical usefulness of these drugs helped to sustain the argument that the sympathetic nervous system was important in the pathogenesis of essential hypertension [44].

The sympathetic nervous system exerts a basal excitatory activity over the kidney. Increases in this activity result in (1) increase in renin secretion, (2) increase in renal tubular sodium reabsorption, and (3) renal vasoconstriction. Experimental studies established the concept that subvasoconstrictor levels of renal sympathetic nerve activity can produce increased renin secretion and increased tubular sodium reabsorption (without changes in renal blood flow and glomerular filtration rate), which result in a shift in the renal-pressure natriuresis function to the right, so that a higher than normal arterial pressure is required to attain sodium balance [12]. There is now convincing evidence that sympathetic nervous system activity is increased in patients with essential hypertension [12,43]. Within this evidence is the finding that normotensive young men with a family history of hypertension have a higher sympathetic nerves activity than those without a family history [45]. During mental stress, sympathetic nerves activity and blood pressure increase in normotensive offspring of parents with essential hypertension, but do not increase in those with normotensive parents $[46,47]$. One-third of patients with borderline hypertension display so-called hyperkinetic circulation, characterized by an elevation in resting heart rate combined with a high cardiac output and an increase in the circulating plasma level of the adrenergic neurotransmitter norepinephrine [44]. In the same way, renal sympathetic nerve activity is augmented two- to threefold (on average) in young patients ( $<45$ years) with essential hypertension $[48,49]$. These patients also show an increased renin release and plasma renin activity. On the other hand, in patients 


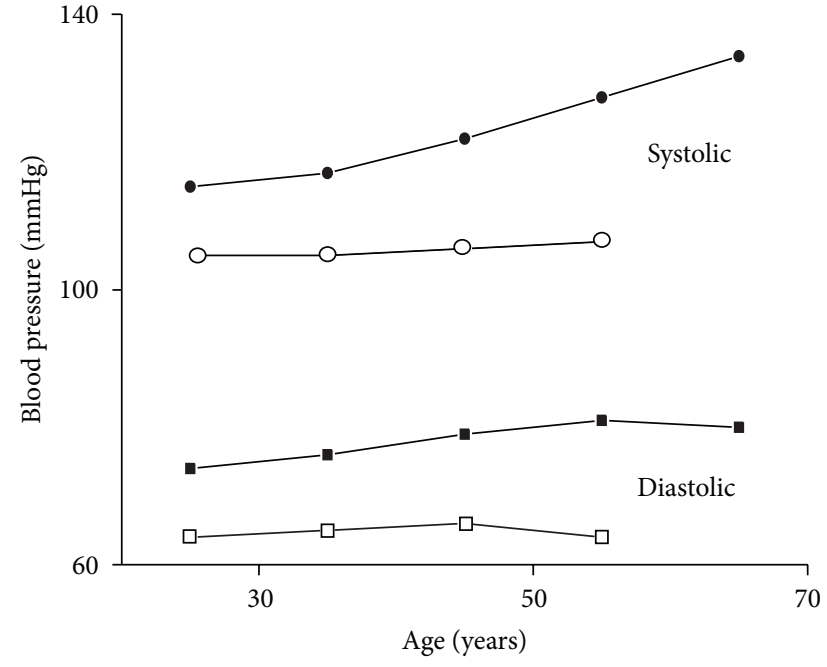

(a)

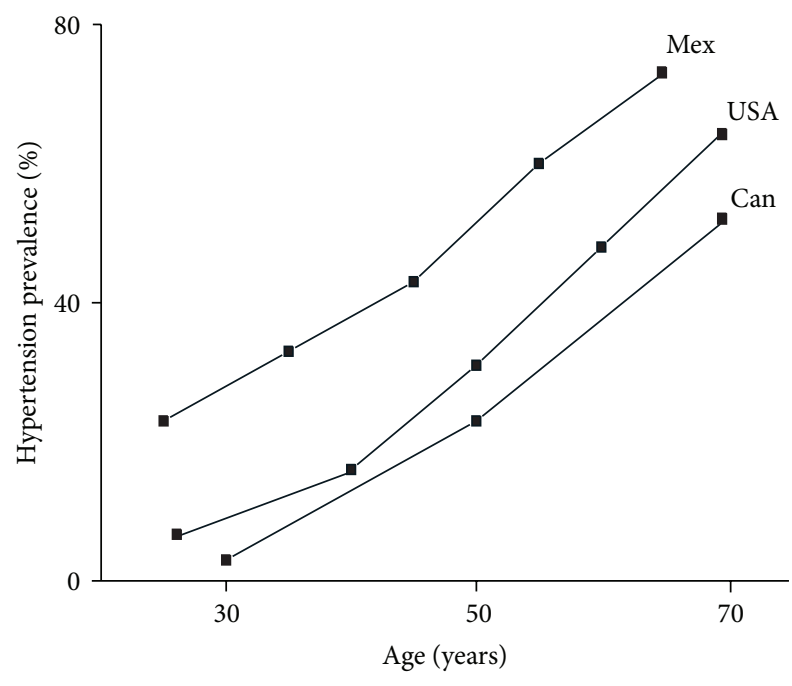

(b)

FIGURE 2: Blood pressure and hypertension during the adulthood. (a) Systolic and diastolic blood pressure mean values (represented in 10-year age group intervals) as a function of age in nonacculturated populations (which do not add salt to food, open symbols) and in an acculturated (the Mexican) population (which does add salt to food, closed symbols). Data adapted from [3, 16]. (b) Hypertension prevalence as a function of age in the populations from Mexico (Mex), the United States of America (USA, both represented in 10-year age group intervals, with the exception of the first point of the USA graph, which represents a 17-year group interval), and Canada (Can, represented in 20-year age group intervals). Data adapted from $[3,17,18]$.

with resistant hypertension, responding inadequately to concurrent treatment with multiple antihypertensive drug classes, radiofrequency ablation of the renal sympathetic nerves lowers blood pressure remarkably [44]. Nowadays, it is deemed that a neurogenic origin (sympathetic activation) of essential hypertension could account for up to $50 \%$ of all cases of high blood pressure [12]. However, increased sympathetic nerves activity is most clearly expressed in the early stages of hypertension development and is less consistent as the time passes $[48,50]$. Once chronic hypertension is installed, and after the early stages of essential hypertension, hypertensive blood pressure levels may be maintained, even in the absence of an increased renal sympathetic nerve activity, mainly by a secondary kidney disease, characterized by glomerulosclerosis, interstitial fibrosis and proteinuria [51, 52].

\section{Origins of Sympathetic Nervous System Activation in Essential Hypertension}

The specific causes of the increased sympathetic activity in essential hypertension are only partially known. Genetic influences (a family history) are evident, and behavioral (as salty food preference), psychosocial (as mental stress) and lifestyle (as physical inactivity) factors appear to be involved $[12,50]$. Of prime importance, no doubt, is obesity. The prevalence of hypertension in middle-age obese subjects is $40-50 \%$. Obesity increases the sympathetic (including the renal sympathetic) nervous system activity through the high sodium intake-related mechanisms that will be discussed below and through other mechanisms, such as hyperleptine$\mathrm{mia}$, that will not be reviewed in this paper $[53,54]$. Likewise, although the prevalence of hypertension increases with aging and $60 \%$ of all adults aged $60-69$ years are hypertensive, owing to the pathogenic factors associated with an increased sympathetic nervous system activity in the elderly, such as high dietary sodium intake and increasing obesity, and only the former will be discussed here $[55,56]$. On the other hand, clinical and epidemiological studies indicate the importance of chronic mental stress in the pathogenesis of essential hypertension [25, 57]. Hypertensive subjects may decrease their blood pressure with a meditation program $[58,59]$. Psychosocial stress can increase the activity of the sympathetic nervous system by potentiating the neural mechanisms activated by a high salt intake [60]. Race and ethnicity may also influence the predisposition to the sensitivity of blood pressure to salt. Black Africans have a higher prevalence of hypertension and more frequent severe hypertension; they also have a greater blood pressure sensitivity to salt intake than do people of other ethnic origins $[25,61]$. Physical inactivity also appears to be important [12]. Aerobic fitness and physical activity are each inversely related to the development of hypertension [62]. Aerobic exercise training in sedentary normotensive and hypertensive people reduces blood pressure and renal and muscle sympathetic nerves activity $[63,64]$.

In hypertensive individuals with their usual salt intake (9-18 g/day) the concentrations of plasma sodium $\left(\left[\mathrm{Na}^{+}\right]_{\mathrm{p}}\right)$ and cerebrospinal fluid (CSF) sodium $\left(\left[\mathrm{Na}^{+}\right]_{\mathrm{csf}}\right)$ are slightly increased (by $0.5-3 \mathrm{mM}$ ), as compared with values observed in the same individual on a low (3-4 g/day) salt intake. The same variation on $\left[\mathrm{Na}^{+}\right]_{\mathrm{p}}$ (and probably in $\left(\left[\mathrm{Na}^{+}\right]_{\mathrm{csf}}\right)$ in normotensive individuals is observed in the same circumstance $[65,66]$. Similar changes in $\left[\mathrm{Na}^{+}\right]_{\mathrm{p}}$ and in $\left[\mathrm{Na}^{+}\right]_{\mathrm{csf}}$ are observed in animal models of hypertension, on a high 


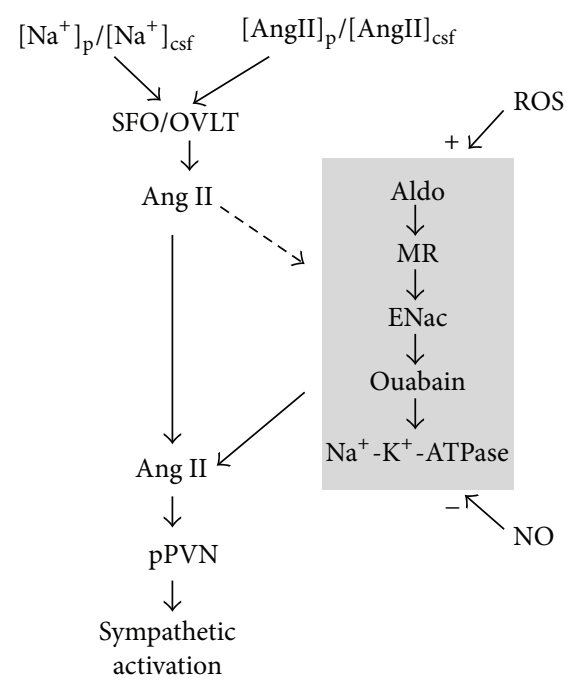

FIGURE 3: Diagram of the central nervous system pathways that may be activated by an increase in one or more of the following agents: circulating $\left[\mathrm{Na}^{+}\right]_{\mathrm{p}},\left[\mathrm{Na}^{+}\right]_{\mathrm{csf}}$, circulating $[\text { Ang II }]_{\mathrm{p}}$ and $[\text { Ang II }]_{\mathrm{csf}}$. Left: agents, acting primarily on the sensorial SFO and OVLT, acutely activate a sympathoexcitatory angiotensinergic pathway that increases the activity of the presympathetic pPVN neurons. Right: chronic increase in these agents also activates, via the SFO and the OVLT, a neuromodulatory pathway, which then maintains enhanced excitatory angiotensinergic activity on the presympathetic pPVN neurons, leading to sustained sympathetic activation and hypertension. See further details in text. Diagram adapted from $[10,19-21]$.

sodium diet $[67,68]$. Studies performed in animal models allow proposing that these increased $\left[\mathrm{Na}^{+}\right]_{\mathrm{p}}$ and/or $\left[\mathrm{Na}^{+}\right]_{\mathrm{csf}}$ activate brain's sodium/osmoreceptors, located mainly at the hypothalamic lamina terminalis, to trigger sympathoexcitation $[67,69]$. These osmoreceptors do not appear to reset significantly with prolonged change in osmolality and therefore can provide a sustained signal to chronically increase sympathetic tone [69]. Similarly, water deprivation-induced increases in osmolality act, at least in part, in the brain to promote sympathoexcitation and support blood pressure [70, 71]. The lamina terminalis comprises three structures aligned in the anteroventral region of the third ventricle. Two of them, the subfornical organ (SFO) and the organum vasculosum of the lamina terminalis (OVLT) are located outside the blood-brain barrier and are sensitive to humoral factors, such as $\mathrm{Na}^{+}$and angiotensin II (Ang II). The third structure, the median preoptic nucleus (MnPO), located within the blood barrier, has reciprocal connections with the two other structures and integrates the humoral sensory information raised in the SFO and OVLT [72-74]. SFO and OVLT increase their activity in response to an increase in $\left[\mathrm{Na}^{+}\right]_{\mathrm{p}}$ and/or $\left[\mathrm{Na}^{+}\right]_{\text {cff }}$, as well as to an increase in plasma and/or CSF Ang II concentration $\left([\text { Ang II }]_{p}\right.$ and $[\text { Ang II }]_{\text {csf }}$, resp. $)[50,67,71,72$, 75]. Diverse studies have shown that SFO and OVLT express $\mathrm{Na}^{+}$conducting nonselective cationic channels (which serve as extracellular $\mathrm{Na}^{+}$-levels sensors) and the Ang II type 1 receptor $\left(\mathrm{AT}_{1}\right.$ receptor), whose expression is enhanced by a high sodium diet and by blood-borne Ang II [73, 76-82]. The latter may explain, at least partially, the antihypertensive and sympathoinhibitory actions of systemic $\mathrm{AT}_{1}$ receptor blockers, such as losartan or valsartan [83-86]. From the SFO and OVLT, perhaps after integration in the MnPO, signals are conveyed from the lamina terminalis to the presympathetic hypothalamic parvocellular neurons of the paraventricular nucleus (pPVN), mainly through Ang II-AT ${ }_{1}$ receptor mediated synapses, though some participation of glutamatergic synapses at the pPVN level has been described (Figure 3, left) $[73,87-90]$. The angiotensinergic nature of most synapses involved in this conduction may explain, at least partially, the antihypertensive and sympathoinhibitory actions of systemic angiotensin-converting enzyme type $1\left(\mathrm{ACE}_{1}\right)$ inhibitors, such as enalapril or captopril [70, 85, 91-93]. At this point, it is necessary to mention that all known components of the RAAS, including the precursor and enzymes required for the production and metabolism of angiotensin peptides and specific $\mathrm{AT}_{1}$ and $\mathrm{AT}_{2}$ receptors, as well as aldosterone (Aldo, which may even cross the blood-brain barrier) and mineralocorticoid receptor (MR), have been identified in the brain [94-97]. It is thought that the direct SFO-, OVLTpPVN pathway described above participates mainly in rapid sympathetic responses to changes in $\left[\mathrm{Na}^{+}\right]_{\mathrm{p}}$ or $\left[\mathrm{Na}^{+}\right]_{\mathrm{csf}}$ or $[\text { Ang II }]_{\mathrm{p}}$ or $[\text { Ang II }]_{\text {csf }}$ and in cardiovascular reflexes or acute psychogenic stress response [73, 74, 98, 99]; however, in generating the chronic sympathoexcitation observed in essential hypertension, another indirect or neuromodulatory SFO-, OVLT-pPVN pathway is involved (Figure 3, right) [10, 19-21, 94]. This neuromodulatory pathway is characteristically dependent on protein phosphorylation and changes in protein expression, and its activation promotes increases in renin, $\mathrm{ACE}_{1}, \mathrm{AT}_{1}$ receptors, Aldo synthase, and NADPH oxidase and decrease in neuronal nitric oxide (NO) synthase in the hypothalamus [100-104]. This polysynaptic pathway is slowly activated (days or weeks) by a chronic increase in $\left[\mathrm{Na}^{+}\right]_{\mathrm{p}}$ and/or $\left[\mathrm{Na}^{+}\right]_{\mathrm{csf}}$ or in $[\text { Ang II }]_{\mathrm{p}}$ and/or $[\text { Ang II }]_{\mathrm{csf}}$ $[10,19-21,105]$ and may be inhibited by the systemic $\mathrm{ACE}_{1}$ inhibitors and $\mathrm{AT}_{1}$ receptor blockers, mentioned above, as well as by systemic spironolactone, an Aldo antagonist [77, 85, $93,106,107]$. This neuromodulatory pathway appears to rise from SFO and OVLT projections directed to the magnocellular neurons of the paraventricular and supraoptic nucleus of the hypothalamus, but its exact anatomical location is uncertain $[21,77,94,108]$. Angiotensinergic conduction, involving Ang II and $\mathrm{AT}_{1}$ receptors, is present at least at the beginning (SFO and OVLT) and end (pPVN) of this pathway [108111], but it involves the sequential participation of diverse neuromodulatory agents, receptors, and ion transport mechanisms, such as Aldo, MR, benzamil-blockable epithelial $\mathrm{Na}^{+}$channels (ENaC), endogenous ouabain-like compounds (ouabain), and ouabain-sensitive $\mathrm{Na}^{+}-\mathrm{K}^{+}$-ATPase $[10,19-$ $21,101,104,105]$. The activity of this pathway is regulated by the balance between the inhibitory influence of NO and the stimulatory influence of reactive oxygen species (ROS), such as superoxide and peroxynitrite; however, as a consequence of the activation of this pathway by the factors mentioned above, production of Ang II and Aldo increases, and this increase, 
by promoting ROS generation and inhibiting NO synthesis, shifts the NO/ROS balance to an enhanced excitation $[10$, $101,105,112-114]$. This abnormal balance may be corrected, at least to some extent, by chronic systemic administration of the gradually, and long-acting dihydropyridine calcium channel blockers azelnidipine, cilnidipine, and amlodipine; and the antidyslipidemic agents simvastatin and pravastatin (chronic peripheral administration of both kind of drugs appears to result in gradual access of drug to the central nervous system) and by regular exercise training; each of them increases NO and decreases ROS, in the brain, thereby partially explaining the antisympathetic and antihypertensive actions of these therapeutics and life style agents [115-124]. The activity of the neuromodulatory pathway maintains an enhanced activity of the pPVN neurons, which increase the sympathetic nerve activity through a direct pathway, mainly vasopressinergic, to the sympathetic preganglionic neurons located at the intermediolateral (IML) cell column of the spinal cord, and through an indirect pathway (vasopressinergic, angiotensinergic, and glutamatergic) to the presympathetic neurons in the rostral ventrolateral medulla (RVLM) $[50,74,125-128]$. In turn, the presympathetic neurons in the RVLM activate the IML sympathetic preganglionic cells through a glutamatergic pathway [129-131]. Hence, activation of the neuromodulatory pathway maintains an increased activity of the pPVN, the RVLM, and the IML presympathetic and sympathetic neurons, leading to sympathoexcitation and hypertension.

\section{Conclusion}

Control of blood pressure requires complex integration of regulatory mechanisms across multiple physiological systems. A sustained increase in arterial pressure therefore reflects a failure of one or more of these controls. The hallmark of essential hypertension, and of all types of chronic hypertension from whatever origin, is an abnormal renalpressure natriuresis relationship, which is shifted to the right, so that sodium equilibrium is obtained at a higher than normal pressure level. This review has emphasized the causal link between an abnormal high salt intake and essential hypertension. A high salt intake (9-12 g/day) is a pleasant component of our current normal diet, but it is abnormal from an evolutionary point of view. This high salt intake induces a slight increase in $\left[\mathrm{Na}^{+}\right]_{\mathrm{p}}$ and/or $\left[\mathrm{Na}^{+}\right]_{\mathrm{csf}}$, which, when sensed by the lamina terminalis sodium/osmoreceptors, triggers, in susceptible individuals, a hypothalamic neuromodulatory signaling chain, activating the sympathetic nervous system. An increased sympathetic nervous system excitatory activity toward the kidney results in increased renin secretion and renal tubular sodium reabsorption and, consequently, in a shift to the right of the pressure natriuresis relationship. Hence, in essential hypertension, the abnormal pressure natriuresis relationship is due to an increased activity of the renal sympathetic nerves. However, this increased renal sympathetic activity is most clearly expressed in the early stages of essential hypertension development and is less consistent as time passes. This review has focused on two of the main etiological and pathophysiological mechanisms responsible for the onset and maintenance of uncomplicated essential hypertension. Once chronic hypertension is installed, it may be maintained, even in the absence of an increased renal sympathetic nerves activity, mainly by a secondary kidney disease.

\section{Conflict of Interests}

The author declares that there is no conflict of interests regarding the publication of this paper.

\section{Acknowledgments}

The author thanks Dr. Dieter Mascher for critical reviewing of the paper and Mr. Cesar Oliver Lara-Figueroa for artwork. This work was partially supported by DGAPA (PAPIIT) UNAM, Grant IN214312 to Dr. Juan J. Bolívar.

\section{References}

[1] P. M. Kearney, M. Whelton, K. Reynolds, P. Muntner, P. K. Whelton, and J. He, "Global burden of hypertension: Analysis of worldwide data," The Lancet, vol. 365, no. 9455, pp. 217-223, 2005.

[2] B. M. Egan, Y. Zhao, and R. N. Axon, "US trends in prevalence, awareness, treatment, and control of hypertension, 1988-2008," Journal of the American Medical Association, vol. 303, no. 20, pp. 2043-2050, 2010.

[3] S. Barquera, I. Campos-Nonato, L. Hernández-Barrera et al., "Hypertension in Mexican adults: results from the national health and nutrition survey 2006," Salud Pública de México, vol. 52, supplement 1, pp. S63-S71, 2010.

[4] K. Tu, Z. Chen, and L. L. Lipscombe, "Prevalence and incidence of hypertension from 1995 to 2005: a population-based study," Canadian Medical Association Journal, vol. 178, no. 11, pp. 14291435, 2008.

[5] F. H. Messerli, B. Williams, and E. Ritz, "Essential hypertension," The Lancet, vol. 370, no. 9587, pp. 591-603, 2007.

[6] J. A. Staessen, J. Wang, G. Bianchi, and W. H. Birkenhäger, "Essential hypertension," The Lancet, vol. 361, no. 9369, pp. 1629-1641, 2003.

[7] O. A. Carretero and S. Oparil, "Essential hypertension. Part I: definition and etiology," Circulation, vol. 101, no. 3, pp. 329-335, 2000.

[8] L. J. Mullins, M. A. Bailey, and J. J. Mullins, "Hypertension, kidney, and transgenics: a fresh perspective," Physiological Reviews, vol. 86, no. 2, pp. 709-746, 2006.

[9] P. Meneton, X. Jeunemaitre, H. E. de Wardener, and G. A. Macgregor, "Links between dietary salt intake, renal salt handling, blood pressure, and cardiovascular diseases," Physiological Reviews, vol. 85, no. 2, pp. 679-715, 2005.

[10] H. Takahashi, M. Yoshika, Y. Komiyama, and M. Nishimura, "The central mechanism underlying hypertension: a review of the roles of sodium ions, epithelial sodium channels, the reninangiotensin-aldosterone system, oxidative stress and endogenous digitalis in the brain," Hypertension Research, vol. 34, no. 11, pp. 1147-1160, 2011.

[11] K. Kurokawa and T. Okuda, "Genetic and non-genetic basis of essential hypertension: maladaptation of human civilization to 
high salt intake," Hypertension Research, vol. 21, no. 2, pp. 67-71, 1998.

[12] G. F. DiBona and M. Esler, "Translational medicine: The antihypertensive effect of renal denervation," The American Journal of Physiology-Regulatory Integrative and Comparative Physiology, vol. 298, no. 2, pp. R245-R253, 2010.

[13] A. C. Guyton, "Blood pressure control-special role of the kidneys and body fluids," Science, vol. 252, no. 5014, pp. 1813$1816,1991$.

[14] A. C. Guyton, T. G. Coleman, A. W. Cowley Jr., R. D. Manning Jr., R. A. Norman Jr., and J. D. Ferguson, "A systems analysis approach to understanding long range arterial blood pressure control and hypertension," Circulation Research, vol. 35, no. 2, pp. 159-176, 1974.

[15] A. C. Guyton, "Renal function curve-a key to understanding the pathogenesis of hypertension," Hypertension, vol. 10, no. 1, pp. 1-6, 1987.

[16] J. J. M. Carvalho, R. G. Baruzzi, P. F. Howard et al., "Blood pressure in four remote populations in the INTERSALT study," Hypertension, vol. 14, no. 3, pp. 238-246, 1989.

[17] L. E. Fields, V. L. Burt, J. A. Cutler, J. Hughes, E. J. Roccella, and P. Sorlie, "The burden of adult hypertension in the United States 1999 to 2000: a rising tide," Hypertension, vol. 44, no. 4, pp. 398404, 2004.

[18] F. H. H. Leenen, J. Dumais, N. H. McInnis et al., "Results of the Ontario survey on the prevalence and control of hypertension," Canadian Medical Association Journal, vol. 178, no. 11, pp. 14411449, 2008.

[19] M. P. Blaustein, F. H. H. Leenen, L. Chen et al., "How NaCl raises blood pressure: a new paradigm for the pathogenesis of saltdependent hypertension," The American Journal of PhysiologyHeart and Circulatory Physiology, vol. 302, no. 5, pp. H1031H1049, 2012.

[20] F. H. H. Leenen, "The central role of the brain aldosterone"ouabain" pathway in salt-sensitive hypertension," Biochimica et Biophysica Acta, vol. 1802, no. 12, pp. 1132-1139, 2010.

[21] B. S. Huang and F. H. H. Leenen, "Mineralocorticoid actions in the brain and hypertension," Current Hypertension Reports, vol. 13, no. 3, pp. 214-220, 2011.

[22] S. B. Eaton, S. B. Eaton III, M. J. Konner, and M. Shostak, "An evolutionary perspective enhances understanding of human nutritional requirements," The Journal of Nutrition, vol. 126, no. 6, pp. 1732-1740, 1996.

[23] D. A. Denton, "Evolutionary aspects of the emergence of aldosterone secretion and salt appetite," Physiological Reviews, vol. 5, no. 2, pp. 245-295, 1995.

[24] J. C. Geerling and A. D. Loewy, "Central regulation of sodium appetite," Experimental Physiology, vol. 93, no. 2, pp. 177-209, 2008.

[25] G. A. Harshfield, Y. Dong, G. K. Kapuku, H. Zhu, and C. D. Hanevold, "Stress-induced sodium retention and hypertension: a review and hypothesis," Current Hypertension Reports, vol. 11, no. 1, pp. 29-34, 2009.

[26] P. Friberg, I. Meredith, G. Jennings, G. Lambert, V. Fazio, and M. Esler, "Evidence for increased renal norepinephrine overflow during sodium restriction in humans," Hypertension, vol. 16, no. 2, pp. 121-130, 1990.

[27] E. Ritz, "The history of salt-aspects of interest to the nephrologist," Nephrology Dialysis Transplantation, vol. 11, no. 6, pp. 969975, 1996.
[28] O. Weller and G. Dumitroaia, "The earliest salt production in the world: an early Neolithic exploitation in Poiana SlatineiLunca, Romania," Antiquity, vol. 79, Project Gallery, no. 306, 2005.

[29] B. Rodriguez-Iturbe, F. Romero, and R. J. Johnson, "Pathophysiological mechanisms of salt-dependent hypertension," The American Journal of Kidney Diseases, vol. 50, no. 4, pp. 655-672, 2007.

[30] D. G. Beevers, "The epidemiology of salt and hypertension," Clinical Autonomic Research, vol. 12, no. 5, pp. 353-357, 2002.

[31] F. J. He and G. A. MacGregor, "A comprehensive review on salt and health and current experience of worldwide salt reduction programmes," Journal of Human Hypertension, vol. 23, no. 6, pp. 363-384, 2009.

[32] "Intersalt: an international study of electrolyte excretion and blood pressure. Results for 24 hour urinary sodium and potassium excretion. Intersalt Cooperative Research Group," The British Medical Journal, vol. 297, no. 6644, pp. 319-328, 1988.

[33] N. K. Hollenberg, "The influence of dietary sodium on blood pressure," Journal of the American College of Nutrition, vol. 25, no. 3, supplement, pp. 240S-246S, 2006.

[34] P. Elliott, J. Stamler, R. Nichols et al., "Intersalt revisited: further analyses of 24 hour sodium excretion and blood pressure within and across populations," The British Medical Journal, vol. 312, no. 7041, pp. 1249-1253, 1996.

[35] Z. Liu, "Dietary sodium and the incidence of hypertension in the chinese population: a review of nationwide surveys," The American Journal of Hypertension, vol. 22, no. 9, pp. 929-933, 2009.

[36] S. Akita, F. M. Sacks, L. P. Svetkey, P. R. Conlin, and G. Kimura, "Effects of the dietary approaches to stop hypertension (DASH) diet on the pressure-natriuresis relationship," Hypertension, vol. 42, no. 1, pp. 8-13, 2003.

[37] F. M. Sacks, L. P. Svetkey, W. M. Vollmer et al., "Effects on blood pressure of reduced dietary sodium and the dietary approaches to stop hypertension (DASH) diet," The New England Journal of Medicine, vol. 344, no. 1, pp. 3-10, 2001.

[38] G. G. Krishna, "Effect of potassium intake on blood pressure," Journal of the American Society of Nephrology, vol. 1, no. 1, pp. 43-52, 1990.

[39] S. R. Smith, P. E. Klotman, and L. P. Svetkey, "Potassium chloride lowers blood pressure and causes natriuresis in older patients with hypertension," Journal of the American Society of Nephrology, vol. 2, no. 8, pp. 1302-1309, 1992.

[40] D. L. Cohen and R. R. Townsend, "The salt controversy and hypertension," Journal of Clinical Hypertension, vol. 14, no. 4, pp. 265-266, 2012.

[41] M. C. Houston, "The Importance of potassium in managing hypertension," Current Hypertension Reports, vol. 13, no. 4, pp. 309-317, 2011.

[42] R. J. Contreras, "Salt taste and disease," The American Journal of Clinical Nutrition, vol. 31, no. 6, pp. 1088-1097, 1978.

[43] G. F. DiBona and U. C. Kopp, "Neural control of renal function," Physiological Reviews, vol. 77, no. 1, pp. 75-197, 1997.

[44] G. Grassi, G. Seravalle, G. Brambilla, and G. Mancia, "The sympathetic nervous system and new nonpharmacologic approaches to treating hypertension: a focus on renal denervation," Canadian Journal of Cardiology, vol. 28, no. 3, pp. 311-317, 2012.

[45] C. Ferrier, H. Cox, and M. Esler, "Elevated total body noradrenaline spillover in normotensive members of hypertensive families," Clinical Science, vol. 84, no. 2, pp. 225-230, 1993. 
[46] G. Noll, R. R. Wenzel, M. Schneider et al., "Increased activation of sympathetic nervous system and endothelin by mental stress in normotensive offspring of hypertensive parents," Circulation, vol. 93, no. 5, pp. 866-869, 1996.

[47] K. C. Light, J. P. Koepke, P. A. Obrist, and P. W. Willis IV, "Psychological stress induces sodium and fluid retention in men at high risk for hypertension," Science, vol. 220, no. 4595, pp. 429-431, 1983.

[48] M. Esler, G. Lambert, and G. Jennings, "Regional norepinephrine turnover in human hypertension," Clinical and Experimental Hypertension A, vol. 11, supplement 1, pp. 75-89, 1989.

[49] M. Esler and D. Kaye, "Increased sympathetic nervous system activity and its therapeutic reduction in arterial hypertension, portal hypertension and heart failure," Journal of the Autonomic Nervous System, vol. 72, no. 2-3, pp. 210-219, 1998.

[50] J. W. Osborn, G. D. Fink, A. F. Sved, G. M. Toney, and M. K. Raizada, "Circulating angiotensin II and dietary salt: converging signals for neurogenic hypertension," Current Hypertension Reports, vol. 9, no. 3, pp. 228-235, 2007.

[51] R. J. Johnson, M. S. Segal, T. Srinivas et al., "Essential hypertension, progressive renal disease, and uric acid: a pathogenetic link?" Journal of the American Society of Nephrology, vol. 16, no. 7, pp. 1909-1919, 2005.

[52] F. Palm and L. Nordquist, "Renal oxidative stress, oxygenation, and hypertension," The American Journal of PhysiologyRegulatory Integrative and Comparative Physiology, vol. 301, no. 5, pp. R1229-R1241, 2011.

[53] K. Ando and M. Fujita, "Reactive oxygen species and the central nervous system in salt-sensitive hypertension: possible relationship with obesity-induced hypertension," Clinical and Experimental Pharmacology and Physiology, vol. 39, no. 1, pp. 111-116, 2012.

[54] G. Z. Kalil and W. G. Haynes, "Sympathetic nervous system in obesity-related hypertension: mechanisms and clinical implications," Hypertension Research, vol. 35, no. 1, pp. 4-16, 2012.

[55] M. C. Acelajado and S. Oparil, "Hypertension in the elderly," Clinics in Geriatric Medicine, vol. 25, no. 3, pp. 391-412, 2009.

[56] D. L. Cohen and R. R. Townsend, "Update on pathophysiology and treatment of hypertension in the elderly," Current Hypertension Reports, vol. 13, no. 5, pp. 330-337, 2011.

[57] A. Flaa, I. K. Eide, S. E. Kjeldsen, and M. Rostrup, "Sympathoadrenal stress reactivity is a predictor of future blood pressure: an 18-year follow-up study," Hypertension, vol. 52, no. 2, pp. 336$341,2008$.

[58] M. V. Rainforth, R. H. Schneider, S. I. Nidich, C. Gaylord-King, J. W. Salerno, and J. W. Anderson, "Stress reduction programs in patients with elevated blood pressure: a systematic review and meta-analysis," Current Hypertension Reports, vol. 9, no. 6, pp. 520-528, 2007.

[59] R. H. Schneider, F. Staggers, C. N. Alexander et al., "A randomized controlled trial of stress reduction for hypertension in older African Americans," Hypertension, vol. 26, no. 5, pp. 820-827, 1995.

[60] D. N. Mayorov, "Brain angiotensin $\mathrm{AT}_{1}$ receptors as specific regulators of cardiovascular reactivity to acute psychoemotional stress," Clinical and Experimental Pharmacology and Physiology, vol. 38, no. 2, pp. 126-135, 2011.

[61] M. H. Weinberger, J. Z. Miller, F. C. Luft, C. E. Grim, and N. Fineberg, "Definitions and characteristics of sodium sensitivity and blood pressure resistance," Hypertension, vol. 8, no. 6, part 2, pp. II127-II134, 1986.
[62] M. R. Carnethon, N. S. Evans, T. S. Church et al., "Joint associations of physical activity and aerobic fitness on the development of incident hypertension: coronary artery risk development in young adults," Hypertension, vol. 56, no. 1, pp. 49-55, 2010.

[63] M. C. Laterza, L. D. N. J. de Matos, I. C. Trombetta et al., "Exercise training restores baroreflex sensitivity in nevertreated hypertensive patients," Hypertension, vol. 49, no. 6, pp. 1298-1306, 2007.

[64] I. T. Meredith, P. Friberg, G. L. Jennings et al., "Exercise training lowers resting renal but not cardiac sympathetic activity in man," Hypertension, vol. 18, no. 5, pp. 575-582, 1991.

[65] F. J. He, N. D. Markandu, G. A. Sagnella, H. E. de Wardener, and G. A. MacGregor, "Plasma sodium: ignored and underestimated," Hypertension, vol. 45, no. 1, pp. 98-102, 2005.

[66] Y. Kawano, K. Yoshida, M. Kawamura et al., "Sodium and noradrenaline in cerebrospinal fluid and blood in salt-sensitive and non-salt-sensitive essential hypertension," Clinical and Experimental Pharmacology and Physiology, vol. 19, no. 4, pp. 235-241, 1992.

[67] J. M. Adams, M. E. Bardgett, and S. D. Stocker, "Ventral lamina terminalis mediates enhanced cardiovascular responses of rostral ventrolateral medulla neurons during increased dietary salt," Hypertension, vol. 54, no. 2, pp. 308-314, 2009.

[68] H. E. de Wardener, F. J. He, and G. A. MacGregor, "Plasma sodium and hypertension," Kidney International, vol. 66, no. 6, pp. 2454-2466, 2004.

[69] V. L. Brooks, J. R. Haywood, and A. K. Johnson, "Translation of salt retention to central activation of the sympathetic nervous system in hypertension," Clinical and Experimental Pharmacology and Physiology, vol. 32, no. 5-6, pp. 426-432, 2005.

[70] E. A. Bourassa and R. C. Speth, "Water deprivation increases angiotensin-converting enzyme but not $\mathrm{AT}_{1}$ receptor expression in brainstem and paraventricular nucleus of the hypothalamus of the rat," Brain Research, vol. 1319, pp. 83-91, 2010.

[71] D. T. B. Pereira-Derderian, R. C. Vendramini, J. V. Menani, and L. A. de Luca Jr., "Water deprivation-induced sodium appetite and differential expression of encephalic c-Fos immunoreactivity in the spontaneously hypertensive rat," The American Journal of Physiology-Regulatory Integrative and Comparative Physiology, vol. 298, no. 5, pp. R1298-R1309, 2010.

[72] S. L. Bealer, C. S. Metcalf, and R. Heyborne, "Increased dietary sodium alters Fos expression in the lamina terminalis during intravenous angiotensin II infusion," Experimental Neurology, vol. 204, no. 1, pp. 299-306, 2007.

[73] M. J. McKinley, A. M. Allen, C. N. May et al., "Neural pathways from the lamina terminalis influencing cardiovascular and body fluid homeostasis," Clinical and Experimental Pharmacology and Physiology, vol. 28, no. 12, pp. 990-992, 2001.

[74] S. D. Stocker, J. L. Osborn, and S. P. Carmichael, "Forebrain osmotic regulation of the sympathetic nervous system," Clinical and Experimental Pharmacology and Physiology, vol. 35, no. 5-6, pp. 695-700, 2008.

[75] D. Mouginot, S. Laforest, and G. Drolet, "Challenged sodium balance and expression of angiotensin type $1 \mathrm{~A}$ receptor mRNA in the hypothalamus of Wistar and Dahl rat strains," Regulatory Peptides, vol. 142, no. 1-2, pp. 44-51, 2007.

[76] C. W. Bourque, S. Ciura, E. Trudel, T. J. E. Stachniak, and R. Sharif-Naeini, "Neurophysiological characterization of mammalian osmosensitive neurones," Experimental Physiology, vol. 92, no. 3, pp. 499-505, 2007. 
[77] A. V. Ferguson, "Angiotensinergic regulation of autonomic and neuroendocrine outputs: critical roles for the subfornical organ and paraventricular nucleus," Neuroendocrinology, vol. 89, no. 4, pp. 370-376, 2009.

[78] J. Monti, M. Schinke, M. Böhm, D. Ganten, M. Bader, and G. Bricca, "Glial angiotensinogen regulates brain angiotensin II receptors in transgenic rats TGR(ASrAOGE)," The American Journal of Physiology-Regulatory Integrative and Comparative Physiology, vol. 280, no. 1, pp. R233-R240, 2001.

[79] M. Noda, "The subfornical organ, a specialized sodium channel, and the sensing of sodium levels in the brain," Neuroscientist, vol. 12, no. 1, pp. 80-91, 2006.

[80] M. Noda, "Hydromineral neuroendocrinology: mechanism of sensing sodium levels in the mammalian brain," Experimental Physiology, vol. 92, no. 3, pp. 513-522, 2007.

[81] J. M. Wang, S. J. Veerasingham, J. Tan, and H. H. Leenen, "Effects of high salt intake on brain $\mathrm{AT}_{1}$ receptor densities in Dahl rats," The American Journal of Physiology-Heart and Circulatory Physiology, vol. 285, no. 5, pp. H1949-H1955, 2003.

[82] S.-G. Wei, Y. Yu, Z.-H. Zhang, and R. B. Felder, "Angiotensin II upregulates hypothalamic $\mathrm{AT}_{1}$ receptor expression in rats via the mitogen-activated protein kinase pathway," The American Journal of Physiology-Heart and Circulatory Physiology, vol. 296, no. 5, pp. H1425-H1433, 2009.

[83] J. P. Collister and M. D. Hendel, "Role of the subfornical organ in the chronic hypotensive response to losartan in normal rats," Hypertension, vol. 41, no. 3 I, pp. 576-582, 2003.

[84] J. P. Collister and M. D. Hendel, "Chronic effects of angiotensin II and $\mathrm{AT}_{1}$ receptor antagonists in subfornical organ-lesioned rats," Clinical and Experimental Pharmacology and Physiology, vol. 32, no. 5-6, pp. 462-466, 2005.

[85] I. H. H. T. Klein, G. Ligtenberg, P. L. Oey, H. A. Koomans, and P. J. Blankestijn, "Enalapril and losartan reduce sympathetic hyperactivity in patients with chronic renal failure," Journal of the American Society of Nephrology, vol. 14, no. 2, pp. 425-430, 2003.

[86] J. Struck, P. Muck, D. Trübger et al., "Effects of selective angiotensin II receptor blockade on sympathetic nerve activity in primary hypertensive subjects," Journal of Hypertension, vol. 20, no. 6, pp. 1143-1149, 2002.

[87] J. S. Bains and A. V. Ferguson, "Paraventricular nucleus neurons projecting to the spinal cord receive excitatory input from the subfornical organ," The American Journal of PhysiologyRegulatory Integrative and Comparative Physiology, vol. 268, no. 3, pp. R625-R633, 1995.

[88] Q. H. Chen and G. M. Toney, "AT 1 -receptor blockade in the hypothalamic PVN reduces central hyperosmolalityinduced renal sympathoexcitation," The American Journal of Physiology-Regulatory Integrative and Comparative Physiology, vol. 281, no. 6, pp. R1844-R1853, 2001.

[89] T. Llewellyn, H. Zheng, X. Liu, B. Xu, and K. P. Patel, "Median preoptic nucleus and subfornical organ drive renal sympathetic nerve activity via a glutamatergic mechanism within the paraventricular nucleus," The American Journal of PhysiologyRegulatory Integrative and Comparative Physiology, vol. 302, no. 4, pp. R424-R432, 2012.

[90] S. D. Stocker and G. M. Toney, "Median preoptic neurones projecting to the hypothalamic paraventricular nucleus respond to osmotic, circulating Ang II and baroreceptor input in the rat," The Journal of Physiology, vol. 568, no. 2, pp. 599-615, 2005.

[91] G. Ligtenberg, P. J. Blankestijn, P. L. Oey et al., "Reduction of sympathetic hyperactivity by enalapril in patients with chronic renal failure," The New England Journal of Medicine, vol. 340, no. 17, pp. 1321-1328, 1999.

[92] S. Minatoguchi, H. Ito, M. Koshiji, K. Masao, S. Hirakawa, and H. Majewski, "Enalapril decreases plasma noradrenaline levels during the cold pressor test in human hypertensives," Clinical and Experimental Pharmacology and Physiology, vol. 19, no. 5, pp. 279-282, 1992.

[93] Z.-H. Zhang, J. Francis, R. M. Weiss, and R. B. Felder, “The renin-angiotensin-aldosterone system excites hypothalamic paraventricular nucleus neurons in heart failure," The American Journal of Physiology-Heart and Circulatory Physiology, vol. 283, no. 1, pp. H423-H433, 2002.

[94] B. S. Huang and F. H. H. Leenen, "The brain renin-angiotensinaldosterone system: A major mechanism for sympathetic hyperactivity and left ventricular remodeling and dysfunction after myocardial infarction," Current Heart Failure Reports, vol. 6, no. 2, pp. 81-88, 2009.

[95] Y. Marc and C. Llorens-Cortes, "The role of the brain reninangiotensin system in hypertension: implications for new treatment," Progress in Neurobiology, vol. 95, no. 2, pp. 89-103, 2011.

[96] M. J. McKinley, A. L. Albiston, A. M. Allen et al., "The brain renin-angiotensin system: location and physiological roles," International Journal of Biochemistry \& Cell Biology, vol. 35, no. 6, pp. 901-918, 2003.

[97] C. D. Sigmund, "Divergent mechanism regulating fluid intake and metabolism by the brain renin-angiotensin system," The American Journal of Physiology-Regulatory Integrative and Comparative Physiology, vol. 302, no. 3, pp. R313-R320, 2012.

[98] J. T. Cunningham, W. D. Knight, S. W. Mifflin, and E. J. Nestler, "An essential role for $\triangle F o s B$ in the median preoptic nucleus in the sustained hypertensive effects of chronic intermittent hypoxia," Hypertension, vol. 60, no. 1, pp. 179-187, 2012.

[99] E. G. Krause, A. D. de Kloet, K. A. Scott et al., "Bloodborne angiotensin II acts in the brain to influence behavioral and endocrine responses to psychogenic stress," Journal of Neuroscience, vol. 31, no. 42, pp. 15009-15015, 2011.

[100] B. S. Huang, R. A. White, A. Y. Jeng, and F. H. H. Leenen, "Role of central nervous system aldosterone synthase and mineralocorticoid receptors in salt-induced hypertension in Dahl salt-sensitive rats," The American Journal of PhysiologyRegulatory Integrative and Comparative Physiology, vol. 296, no. 4, pp. R994-R1000, 2009.

[101] B. S. Huang, H. Zheng, J. Tan, K. P. Patel, and F. H. H. Leenen, "Regulation of hypothalamic renin-angiotensin system and oxidative stress by aldosterone," Experimental Physiology, vol. 96, no. 10, pp. 1028-1038, 2011.

[102] M. Nishimura, A. Nanbu, K. Ohtsuka et al., "Sodium intake regulates renin gene expression differently in the hypothalamus and kidney of rats," Journal of Hypertension, vol. 15, no. 5, pp. 509-516, 1997.

[103] M. Nishimura, K. Ohtsuka, H. Takahashi, and M. Yoshimura, "Role of FMRFamide-activated brain sodium channel in saltsensitive hypertension," Hypertension, vol. 35, no. 1, pp. 443$450,2000$.

[104] Z.-H. Zhang, Y. Yu, Y.-M. Kang, S.-G. Wei, and R. B. Felder, "Aldosterone acts centrally to increase brain renin-angiotensin system activity and oxidative stress in normal rats," The American Journal of Physiology-Heart and Circulatory Physiology, vol. 294, no. 2, pp. H1067-H1074, 2008.

[105] B. Xue, T. G. Beltz, Y. Yu et al., "Central interactions of aldosterone and angiotensin II in aldosterone- and angiotensin 
II-induced hypertension," The American Journal of PhysiologyHeart and Circulatory Physiology, vol. 300, no. 2, pp. H555H564, 2011.

[106] D. V. Menon, D. Arbique, Z. Wang, B. Adams-Huet, R. J. Auchus, and W. Vongpatanasin, "Differential effects of chlorthalidone Versus spironolactone on muscle sympathetic nerve activity in hypertensive patients," Journal of Clinical Endocrinology and Metabolism, vol. 94, no. 4, pp. 1361-1366, 2009.

[107] D. W. Wray and M. A. Supiano, "Impact of aldosterone receptor blockade compared with thiazide therapy on sympathetic nervous system function in geriatric hypertension," Hypertension, vol. 55, no. 5, pp. 1217-1223, 2010.

[108] B. S. Huang, S. Ahmadi, M. Ahmad, R. A. White, and F. H. H. Leenen, "Central neuronal activation and pressor responses induced by circulating ANG II: Role of the brain aldosterone"ouabain" pathway," The American Journal of Physiology-Heart and Circulatory Physiology, vol. 299, no. 2, pp. H422-H430, 2010.

[109] B. S. Huang, W. J. Cheung, H. Wang, J. Tan, R. A. White, and F. H. H. Leenen, "Activation of brain renin-angiotensinaldosterone system by central sodium in Wistar rats," The American Journal of Physiology-Heart and Circulatory Physiology, vol. 291, no. 3, pp. H1109-H1117, 2006.

[110] A. Gabor and F. H. H. Leenen, "Mechanisms in the PVN mediating local and central sodium-induced hypertension in Wistar rats," The American Journal of Physiology-Regulatory Integrative and Comparative Physiology, vol. 296, no. 3, pp. R618-R630, 2009.

[111] A. Gabor and F. H. H. Leenen, "Mechanisms mediating sodiuminduced pressor responses in the PVN of Dahl rats," The American Journal of Physiology-Regulatory Integrative and Comparative Physiology, vol. 301, no. 5, pp. R1338-R1349, 2011.

[112] Y.-F. Li, W. Wang, W. G. Mayhan, and K. P. Patel, "Angiotensinmediated increase in renal sympathetic nerve discharge within the PVN: role of nitric oxide," The American Journal of Physiology-Regulatory Integrative and Comparative Physiology, vol. 290, no. 4, pp. R1035-R1043, 2006.

[113] C. A. Northcott, S. Billecke, T. Craig et al., "Nitric oxide synthase, ADMA, SDMA, and nitric oxide activity in the paraventricular nucleus throughout the etiology of renal wrap hypertension," The American Journal of Physiology-Heart and Circulatory Physiology, vol. 302, no. 11, pp. H2276-H2284, 2012.

[114] B. Xue, T. G. Beltz, R. F. Johnson, F. Guo, M. Hay, and A. K. Johnson, "PVN adenovirus-siRNA injections silencing either $\mathrm{NOX}_{2}$ or $\mathrm{NOX}_{4}$ attenuate aldosterone/NaCl-induced hypertension in mice," The American Journal of PhysiologyHeart and Circulatory Physiology, vol. 302, no. 3, pp. H733H741, 2012.

[115] D. Agarwal, M. A. Welsch, J. N. Keller, and J. Francis, "Chronic exercise modulates RAS components and improves balance between pro-and anti-inflammatory cytokines in the brain of SHR," Basic Research in Cardiology, vol. 106, no. 6, pp. 10691085, 2011.

[116] J. P. Fisher and P. J. Fadel, “Therapeutic strategies for targeting excessive central sympathetic activation in human hypertension," Experimental Physiology, vol. 95, no. 5, pp. 572-580, 2010.

[117] L. Gao, W. Wang, Y.-L. Li et al., "Simvastatin therapy normalizes sympathetic neural control in experimental heart failure: roles of angiotensin II type 1 receptors and NAD(P)H oxidase," Circulation, vol. 112, no. 12, pp. 1763-1770, 2005.
[118] L. Gao, W. Wang, and I. H. Zucker, "Simvastatin inhibits central sympathetic outflow in heart failure by a nitric-oxide synthase mechanism," Journal of Pharmacology and Experimental Therapeutics, vol. 326, no. 1, pp. 278-285, 2008.

[119] Y. Hirooka, Y. Kimura, M. Nozoe, Y. Sagara, K. Ito, and K. Sunagawa, "Amlodipine-induced reduction of oxidative stress in the brain is associated with sympatho-inhibitory effects in stroke-prone spontaneously hypertensive rats," Hypertension Research, vol. 29, no. 1, pp. 49-56, 2006.

[120] Y. Kimura, Y. Hirooka, Y. Sagara, and K. Sunagawa, "Longacting calcium channel blocker, azelnidipine, increases endothelial nitric oxide synthase in the brain and inhibits sympathetic nerve activity," Clinical and Experimental Hypertension, vol. 29, no. 1, pp. 13-21, 2007.

[121] T. Kishi, Y. Hirooka, S. Konno, and K. Sunagawa, "Cilnidipine inhibits the sympathetic nerve activity and improves baroreflex sensitivity in patients with hypertension," Clinical and Experimental Hypertension, vol. 31, no. 3, pp. 241-249, 2009.

[122] S. Konno, Y. Hirooka, S. Araki, Y. Koga, T. Kishi, and K. Sunagawa, "Azelnidipine decreases sympathetic nerve activity via antioxidant effect in the rostral ventrolateral medulla of stroke-prone spontaneously hypertensive rats," Journal of Cardiovascular Pharmacology, vol. 52, no. 6, pp. 555-560, 2008.

[123] F. H. Leenen, M. Ruzicka, and B. S. Huang, "Central sympathoinhibitory effects of calcium channel blockers," Current Hypertension Reports, vol. 3, no. 4, pp. 314-321, 2001.

[124] H. Zheng, Y.-F. Li, K. G. Cornish, I. H. Zucker, and K. P. Patel, "Exercise training improves endogenous nitric oxide mechanisms within the paraventricular nucleus in rats with heart failure," The American Journal of Physiology-Heart and Circulatory Physiology, vol. 288, no. 5, pp. H2332-H2341, 2005.

[125] P. Kc, K. V. Balan, S. S. Tjoe et al., "Increased vasopressin transmission from the paraventricular nucleus to the rostral medulla augments cardiorespiratory outflow in chronic intermittent hypoxia-conditioned rats," The Journal of Physiology, vol. 588, no. 4, pp. 725-740, 2010.

[126] S. D. Stocker, J. R. Simmons, R. L. Stornetta, G. M. Toney, and P. G. Guyenet, "Water deprivation activates a glutamatergic projection from the hypothalamic paraventricular nucleus to the rostral ventrolateral medulla," Journal of Comparative Neurology, vol. 494, no. 4, pp. 673-685, 2006.

[127] S. Pyner, "Neurochemistry of the paraventricular nucleus of the hypothalamus: implications for cardiovascular regulation," Journal of Chemical Neuroanatomy, vol. 38, no. 3, pp. 197-208, 2009.

[128] T. Tagawa and R. A. L. Dampney, "AT 1 receptors mediate excitatory inputs to rostral ventrolateral medulla pressor neurons from hypothalamus," Hypertension, vol. 34, no. 6, pp. 1301-1307, 1999.

[129] L. Hu, D.-N. Zhu, Z. Yu, J. Q. Wang, Z.-J. Sun, and T. Yao, "Expression of angiotensin II type $1\left(\mathrm{AT}_{1}\right)$ receptor in the rostral ventrolateral medulla in rats," Journal of Applied Physiology, vol. 92, no. 5, pp. 2153-2161, 2002.

[130] I. J. Llewellyn-Smith, C. L. Martin, and J. B. Minson, "Glutamate and GABA content of calbindin-immunoreactive nerve terminals in the rat intermediolateral cell column," Autonomic Neuroscience, vol. 98, no. 1-2, pp. 7-11, 2002.

[131] S. F. Morrison, J. Callaway, T. A. Milner, and D. J. Reis, "Rostral ventrolateral medulla: a source of the glutamatergic innervation of the sympathetic intermediolateral nucleus," Brain Research, vol. 562, no. 1, pp. 126-135, 1991. 


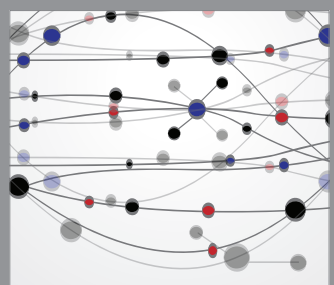

The Scientific World Journal
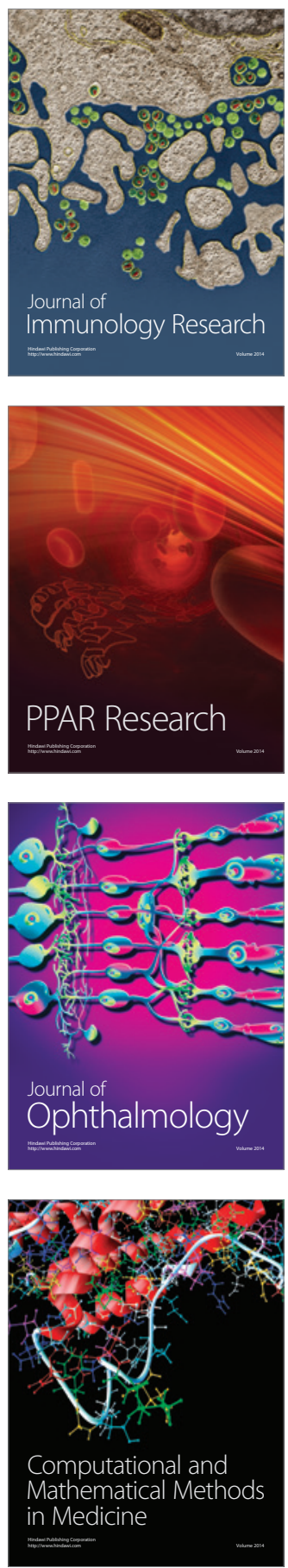

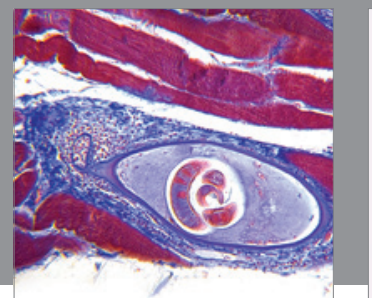

Gastroenterology

Research and Practice
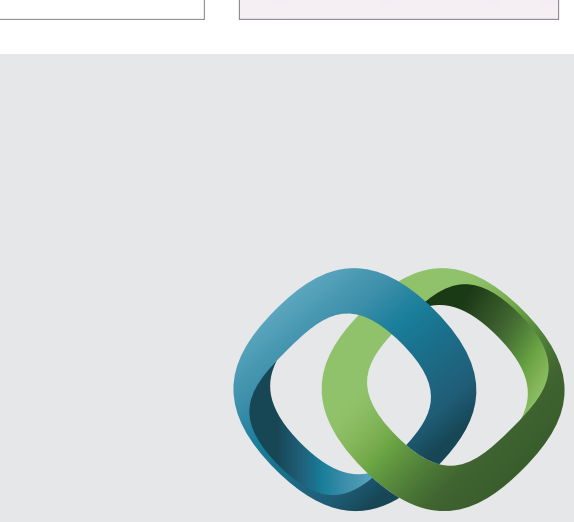

\section{Hindawi}

Submit your manuscripts at

http://www.hindawi.com
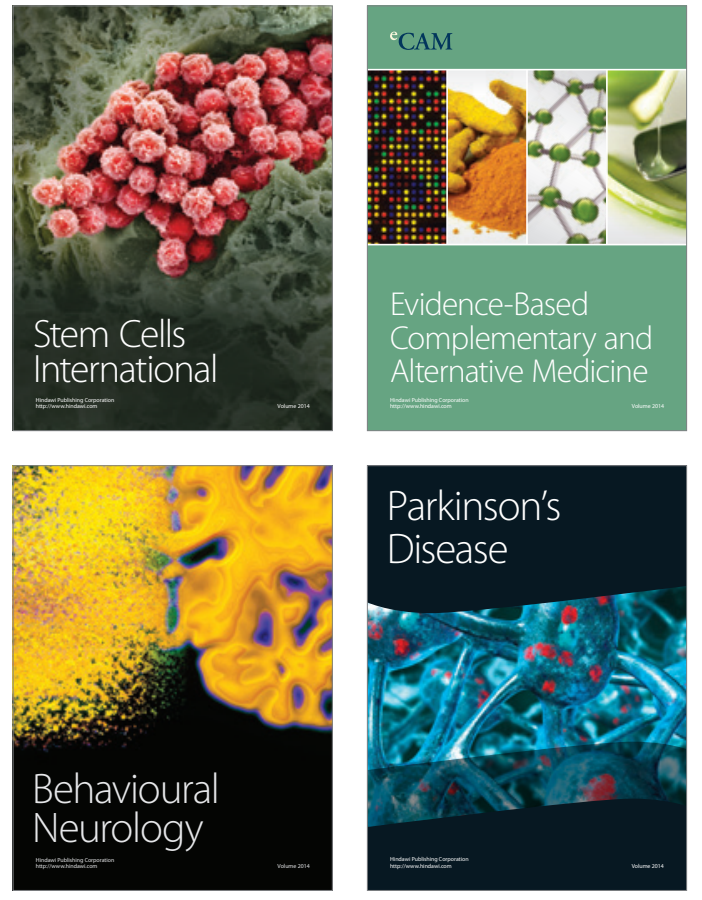
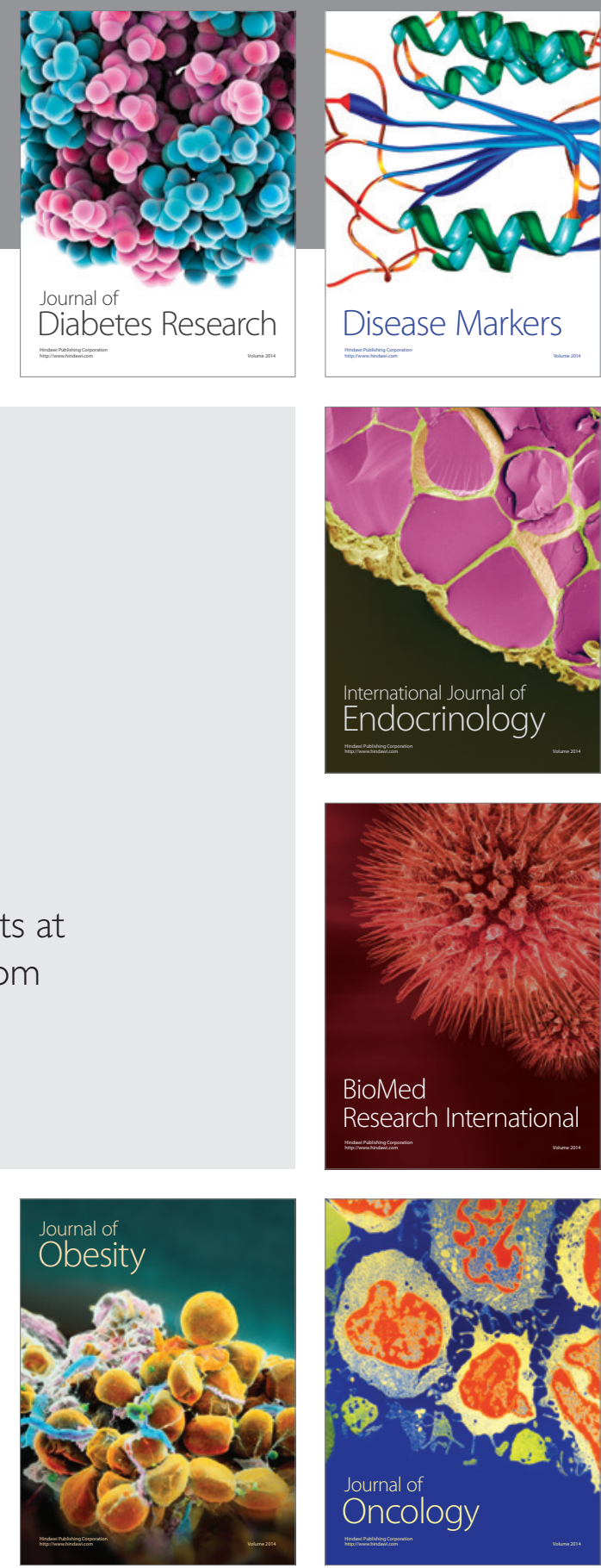

Disease Markers
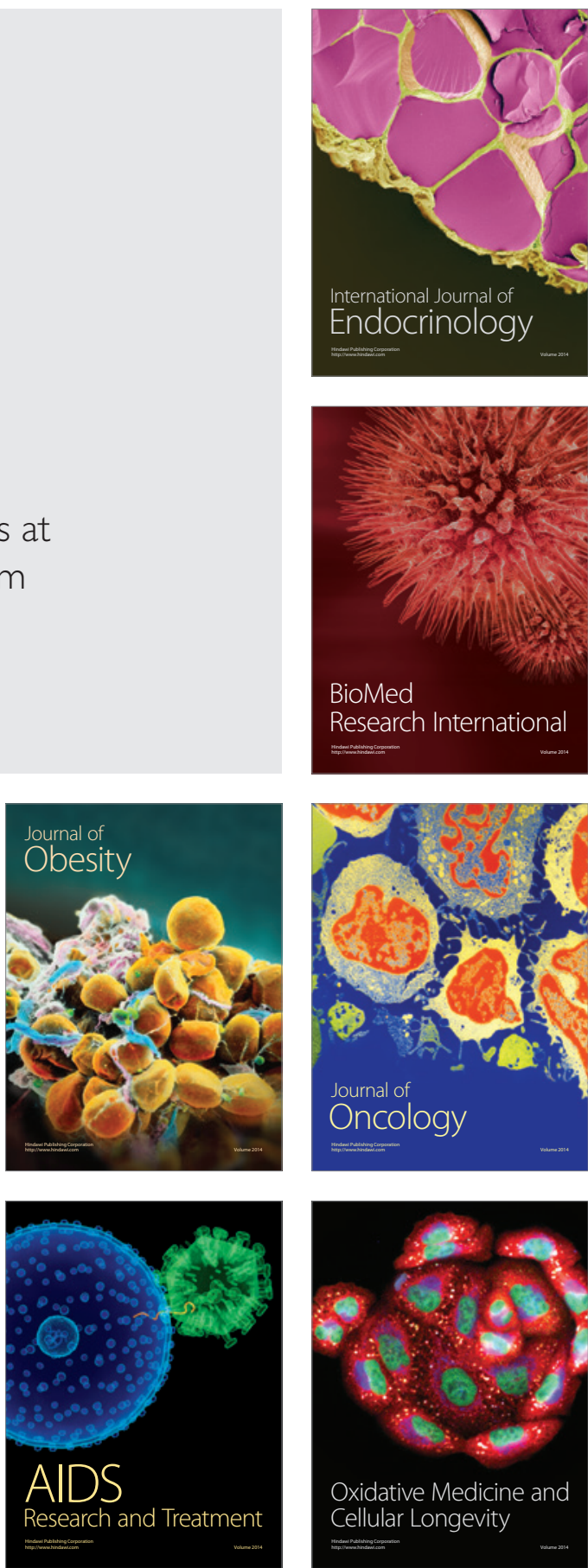